\title{
Harmonized biosafety regulations are key to trust building in regional agbiotech partnerships: the case of the Bt cotton project in East Africa
}

\author{
Obidimma C Ezezika ${ }^{1,2,3^{*}}$, Justin Mabeya ${ }^{1}$, Abdallah S Daar ${ }^{1,4,5}$
}

\begin{abstract}
Background: The Bacillus thuringiensis (Bt) cotton public-private partnership (PPP) project in East Africa was designed to gather baseline data on the effect of Bt cotton on biodiversity and the possibility of gene flow to wild cotton varieties. The results of the project are intended to be useful for Kenya, Uganda, and Tanzania when applying for biosafety approvals. Using the backdrop of the different biosafety regulations in the three countries, we investigate the role of trust in the Bt cotton partnership in East Africa.

Methods: Data were collected by reviewing relevant project documents and peer-reviewed articles on Bt cotton in Tanzania, Kenya and Uganda; conducting face-to-face interviews with key informants of the project; and conducting direct observations of the project. Data were analyzed based on recurring and emergent themes to create a comprehensive narrative on how trust is understood and built among the partners and with the community.

Results: We identified three factors that posed challenges to building trust in the Bt cotton project in East Africa: different regulatory regimes among the three countries; structural and management differences among the three partner institutions; and poor public awareness of GM crops and negative perceptions of the private sector. The structural and management differences were said to be addressed through joint planning, harmonization of research protocols, and management practices, while poor public awareness of GM crops and negative perceptions of the private sector were said to be addressed through open communication, sharing of resources, direct stakeholder engagement and awareness creation. The regulatory differences remained outside the scope of the project.

Conclusions: To improve the effectiveness of agbiotech PPPS, there is first a need for a regulatory regime that is acceptable to both the public and private sector partners. Second, early and continuous joint planning; sharing of information; and transparency encourages accountability and fosters trust building. Third, direct stakeholder engagement and awareness creation builds trust between project partners and the community. A concern raised by the interviewees was the absence of a regulatory framework in Tanzania, which deterred active private sector participation in the project.
\end{abstract}

\section{Background}

The Bacillus thuringiensis (Bt) cotton project in East Africa was designed to gather baseline data on the effect of Bt cotton on above- and below-ground biodiversity and the possibility of gene flow to wild cotton varieties. The potential consumers of the project's results are the regulators in three East African countries-Tanzania,

\footnotetext{
* Correspondence: obidimma.ezezika@srcglobal.org

'Sandra Rotman Centre, University Health Network and University of

Toronto, Toronto, Ontario, Canada

Full list of author information is available at the end of the article
}

Kenya, and Uganda-as well as others interested in agbiotech regulation.

In Tanzania, cotton comprises the third largest agricultural export after coffee and tobacco [1]. However, the average production per hectare of $750 \mathrm{~kg}$ is far below the world average of $2000 \mathrm{~kg} / \mathrm{ha}$ [2]. Cotton in Tanzania is cultivated by approximately 500,000 smallholder farmers [2]. One of the major challenges to cotton production in Tanzania is the cotton bollworm (Helicoverpa armigera), which is currently managed by use of pesticides (which

\section{Ciomed Central}


pose health and environmental risks to the users), among other methods.

Cotton in Kenya is primarily grown by approximately 30,000 small-scale farmers [3]. Over the last decade, cotton production in Kenya has steadily declined [4], partly because of pests and diseases, key among them the cotton bollworm [5]. Management of the pest is primarily done, as in Tanzania, by use of pesticides (6 to 8 sprays per season) that, while effective, pose health and environmental risks to the users.

In some parts of Uganda, the current yield of cotton is approximately $400 \mathrm{~kg} / \mathrm{ha}$, which is far below the production potential [6]. As is the case in the other East African countries, a major threat to production in Uganda is the cotton bollworm, which has been reported to cause losses in yield as high as $40 \%$ in parts of the country [6].

To address the challenge posed by the cotton bollworm and other insect pests, the three East African countries have considered the use of genetically modified (GM) cotton. In Kenya, trials for Bt cotton were approved by the National Biosafety Committee (NBC) in 2003. The project, which is currently running, is being undertaken jointly by the Kenya Agricultural Research Institute (KARI) and the multinational seed company, Monsanto. The GM cotton varieties being tested in Kenya are intended to control the cotton bollworm. This flagship GM technology is expected to be commercialized in 2014 [7] under the new biosafety law that was passed in 2009, which allows for the commercialization of GM crops [8].

In Uganda, the National Agricultural Research Organization (NARO) has been conducting field trials of Bt cotton since 2009 for both insect and herbicide resistance in collaboration with Monsanto under the National Biosafety regulations, while a comprehensive biosafety law is being developed [9].

In Tanzania, the idea of using GM cotton has attracted support from top government policy makers in the Ministry of Agriculture and Food Security who have stated that the government is committed to adopting improved technologies including genetic engineering to increase cotton yields, reduce farm costs, and increase profits [10]. This will be subject to a review of the environmental laws governing GM products to enable the commercial introduction of such technologies [11]. Yet, the National Biosafety Framework (NBF), the system in place governing biosafety in Tanzania, contains a strict liability clause, which has been considered punitive to those wishing to develop and commercialize GM technologies in Tanzania. The clause states: "A person who imports, arranges transit, makes contained use of, releases or places on the market a genetically modified organism (GMO) or product of a GMO shall be strictly liable for any harm caused by such a GMO or product of a GMO. The harm shall be fully compensated" [12]. The response to this clause has been limited interest by private companies to partner with Tanzanian institutions in developing such technologies, including Bt cotton. The existing legal framework in Tanzania does provide for commercialization, but efforts to ensure that there is progress in agbiotech research have been stalled by this clause. In this article we report on how the differences in biosafety regulations among the three East African countries affected trust building between the public and private sector players in the project.

\section{The development of the Bt cotton project}

The Bt cotton project in East Africa was initiated in 2006 following a successful grant application by a joint team of scientists from Tanzania, Kenya and Uganda in collaboration with agbiotech experts from the United States [13]. The goal of the three-year project was twofold: to study the effect of Bt cotton on arthropod biodiversity in East Africa and to study the possibility of gene flow from Bt cotton to wild cotton varieties. The results of the study are expected to serve as baseline data that may be useful to the regulatory organizations in the region when considering biosafety approvals for Bt cotton [13].

Funding for the project was provided by the United States Agency for International Development (USAID) through the Biotechnology and Biodiversity Interface (BBI) of the Program for Biosafety Systems (PBS) of the International Food Policy Research Institute (IFPRI). The lead partner in the project is the Tropical Pesticide Research Institute (TPRI) in Tanzania. Others include KARI in Kenya; Makerere University and NARO in Uganda; and the Agricultural Innovation Research Foundation (AIRF) in Tanzania [13]. Table 1 summarizes the roles and responsibilities of the project partners (refer to Additional file 1 for brief profiles of the implementing partner institutions).

\section{Trust in agbiotech PPPs}

The success of agbiotech projects depends on the ability of partners to engage in long-term collaborations, among other factors. Since the involvement of multinational private companies has been found to breed distrust, the presence of trust is critical in agbiotech PPP projects $[14,15]$. The negative consequences of such distrust are compounded in the context of GM food. For example, there is fear, among public partners, pertaining to corporate control of the seed market by genetic engineering companies [13]. This case study investigates the role of trust in the Bt cotton in East Africa partnership from the project's conception to its end. The three specific objectives of this study are to: 1 ) describe trust-building practices in the development of the project; 2 ) describe the challenges associated with trust-building in the partnership; and 3) determine what makes these practices effective or ineffective. 
Table 1 Bt cotton project partner and collaborator responsibilities

\begin{tabular}{|c|c|}
\hline Partners & Role \\
\hline $\begin{array}{l}\text { Tropical Pesticide Research Institute, } \\
\text { Tanzania }\end{array}$ & Conducting gene flow studies from Bt cotton to wild indigenous cotton varieties in the region \\
\hline $\begin{array}{l}\text { Kenya Agricultural Research Institute, } \\
\text { Kenya }\end{array}$ & $\begin{array}{l}\text { Conducting studies on the effect of Bt cotton on both the above-ground and under-ground non-target } \\
\text { arthropod species }\end{array}$ \\
\hline Makerere University, Uganda & Management and disbursement of the project funds \\
\hline $\begin{array}{l}\text { National Agricultural Research } \\
\text { Organization, Uganda }\end{array}$ & $\begin{array}{l}\text { Conducting studies on the effect of Bt cotton on both the above-ground and under-ground non-target } \\
\text { arthropod species }\end{array}$ \\
\hline $\begin{array}{l}\text { Agricultural Innovation Research } \\
\text { Foundation, Tanzania }\end{array}$ & $\begin{array}{l}\text { Conducting risk assessment of the Bt cotton technologies, training of stakeholders and community } \\
\text { engagement and awareness }\end{array}$ \\
\hline Biotechnology and Biodiversity Interface & Provided funding for the project \\
\hline Collaborator & Role \\
\hline Monsanto & $\begin{array}{l}\text { Allowed the trials meant to be conducted by TPRI in Tanzania to run next to the Bt cotton trials at KARI, } \\
\text { Thika Research Station in Kenya }\end{array}$ \\
\hline
\end{tabular}

By identifying barriers to trust and trust-enhancing practices, this study provides insight for potential funders, researchers, farmers and others involved in agbiotech initiatives. The results of this study will be useful in informing PPPs involved in agricultural biotechnology on the need for building and maintaining trust among the partners and with the community.

\section{Methods}

Data were collected by conducting interviews with key informants knowledgeable about the project; reviewing publicly available project documents and research articles; and conducting direct observations. We received Research Ethics Board (REB) approval from the University Health Network, University of Toronto for conducting the case study. Interviewees were identified by first making a list of key individuals associated with the project based on the stakeholder groups identified in the case study research protocol. This list was further populated through snowball sampling using stakeholder informants familiar with the Sandra Rotman Centre's Social Audit Project [16]. Social auditing is a process whereby an audit team collects, analyses, and interprets descriptive, quantitative and qualitative information from stakeholders to produce an account of a project's ethical, social, cultural and commercialization performance and impact. The social audit helps foster improved management practices, accountability and transparency, which in turn help to build trust both among the partners in a project as well as between the project and the public. A total of 16 individuals were identified through this process, of which ten, who were most relevant to this case study, were invited for interview. Eight individuals in total were interviewed as two of those invited were not available. Potential interviewees were sent an invitation, which included an explanation of the case study series, to participate in the interview. Informed consent was sought from the potential interviewees by obtaining duplicate signed copies of written consent. Those who consented to participate were informed that the interview would be digitally recorded, transcribed verbatim and then analyzed.

The interviews took place in Mozambique, Uganda, Kenya and Tanzania - as per the convenience of the interviewees. The interviews were conducted using a semistructured interview guide and each lasted approximately one hour and a half. The interviewees included representatives from the Monsanto Company, TPRI, KARI, AIRF, PBS, Ministry of Agriculture in Tanzania, Vice President's Office and Ministry of Environment in Tanzania, and Makerere University. The interviews explored the partners' and the public's general perceptions of trust within the agbiotech PPP, apparent challenges to building trust, and trust-building practices in the PPP. Interviewees were also asked for their suggestions on how to improve trust in agbiotech PPPs (refer to Additional file 2 for sample questions from the interview guide).

The data were analyzed by identifying recurring and emergent themes from the transcripts, relevant literature and observations. All the data were triangulated to create a comprehensive narrative on how trust is understood and built among the partners and with the community. The case study methodology used in this study was adapted from Yin 2003 [17].

\section{Results and discussion}

Our analysis of the data reveals that the trust-building issues faced in this project revolve around challenges pertaining to the biosafety regulations in the region. Key among them is the absence of a regulatory framework in Tanzania, which is not conducive to the development and commercialization of GM technology and the evolving nature of the regulatory process in the three countries. While there have been no studies showing that the absence of a favorable biosafety law has been a hindrance 
to commercialization of the GM technologies in East Africa, it has been observed that the absence of clear biosafety regulations can lead to distrust among the various stakeholders [18].

\section{Stakeholders' understanding of trust}

In order to put into context the interviewees' understanding of trust-building challenges and practices, the interviewees were asked to define the word trust and describe its elements in the context of the partnership. Trust was described by the interviewees as the ability to have confidence in people and institutions and as a two-way positive relationship. Trust could be built upon an agreement that does not necessarily have to be formal, and delivery of results is evidence that trust is present. Overall, the interviewees understood trust to be the ability of the parties in a mutual agreement to have confidence in each other and be committed to work in a transparent and accountable manner in order to achieve the objectives of the agreement to their mutual satisfaction.

Based on the results of this study, we have derived three key lessons that would provide insight to partners in other agbiotech PPPs on fostering trust among partners and with the community and on enhancing regulatory processes.

\section{Regulatory regimes acceptable to both public and private sector parties are a foundation for building trust in agbiotech PPP projects \\ Inconsistencies and barriers in regulatory frameworks}

The respective regulatory arrangements in the three countries help explain the degree of willingness with which the private sector engaged with the partners from each of the three countries. Although the Bt cotton project in East Africa began with the BBI grant in 2006, the project activities in each country began at different times due to differences in the biosafety regulations and the management of biosafety matters among the three East African countries. Studies in Kenya began in earnest in 2007 while those in Uganda began in 2008, both having been delayed by the biosafety approval processes-which, in some instances, were perceived by the project management as a deliberate move by the regulators to slow down the process because of suspicion of incompetence on the part of the former. To forestall these suspicions the project management made efforts to address any foreseeable regulatory concerns before applying for regulatory approvals. In Tanzania, the delay was due to what the private partner considered to be unfavorable legislation in the country, which prevented Monsanto from providing the $\mathrm{Bt}$ cotton technology for trials in the country.

We observed that the regulatory differences and their impact on project activities did not threaten trust among the public institutions implementing the project. The interviewees from the public institutions did not point to any factor that could compromise trust among them, but they reported of a mutual working relationship among them. However, in order for the private sector to be fully engaged as a partner and active in the project activities, there was a need not only for a consistent regulatory regime in the three countries but one that is acceptable to all stakeholders. The interviewee from Monsanto emphasized that trust develops when parties deliver on commitments that are based on an acceptable biosafety legal framework. The good relationship between KARI and Monsanto, for example, shed light on two factors that contributed to trust building between the two. First, there is a favorable biosafety legal framework in Kenya [8], which enabled Monsanto to enter into an agreement with KARI. Second, the technical staff were not only competent but also committed to, and passionate about, delivering on the agreed upon milestones. Subsequently, as the objectives of the agreement were achieved, trust between the partners grew. Similarly, the interviewee from Monsanto acknowledged that, in Uganda, the National Biotechnology and Biosafety Policy 2008 [19] provided a suitable environment for private sector engagement which served as a foundation on which trust building practices would be anchored.

Contrastingly, lack of a favorable regulatory environment in Tanzania resulted in a case in which the field trials of $\mathrm{Bt}$ cotton scheduled to be conducted in Tanzania were transferred to Kenya due to the latter's more favorable regulatory regime. There was, as a result, no direct contact between TPRI and Monsanto in this project, according to an interviewee from the TPRI, and therefore no possibility of trust building between the two institutions.

We observe that the aforementioned inconsistencies in, and barriers to, the regulatory process posed significant hurdles to trust building among partners and with the community. According to the interviewees, there is a need for a legal framework conducive to private sector participation, which will serve as a foundation for trust building. Individual country regulatory frameworks are therefore necessary for the progress and success of GM crop development projects. For example, even if the harmonized research protocols render the results of the Tanzanian trials in Kenya acceptable to regulators in Tanzania, access to the private sector technologies for broader adoption of the GM technologies will require a regulatory regime that is more acceptable than it currently is and encourages the partners' confidence in the process.

\section{Baseline trust and legislation as foundations for trust building}

There were divergent views from the public and private sector regarding the basis on which trust among the partners in the project grew. We deduce that this may 
be due to differences in the working cultures of the two sectors. The interviewees from the public institutions suggested that their initial engagement was based on the presence of what they described as 'baseline trust,' on which further trust building could take place, while the private sector emphasized that trust grew based on a negotiated agreement among partners working within an acceptable legislative framework.

Immediately upon the project's inception, the public institutions decided to collaborate on an understanding that they will be able to work together to build trust. According to a scientist from PBS (the funding institution that also initiated the development of the joint proposal), this early engagement was based on some baseline trust on which the parties further built trust. 'Baseline trust' was understood by the scientist from PBS to be a particular level of trust between parties which is partly based on knowledge of past collaborations in similar projects and determined by the willingness of the parties to participate in the joint application of the grant (i.e., the initial engagement). Later on, the public institutions put in place structural management practices, including harmonization of research protocols and organizational management processes, which contributed to enhancing trust among themselves and progress in the project.

However, an interviewee from Monsanto underscored the need for a legal framework that would facilitate their active participation, emphasizing the fact that, in agbiotech PPPs, the existing legislation in a country defines the nature of the relationship among partners. The interviewee from Monsanto stated that the relationship among the partners is influenced less by trust than by legality; specifically, it is within a relationship bound by clear legislation that parties engage, negotiate and sign agreements stipulating partner roles and obligations. The presence or lack of trust, then, is determined by what ensues from such agreements (i.e., whether or not the partners deliver on agreements). For example, in the aforementioned relationship between KARI and Monsanto, trust between the two institutions was built partly as a result of the parties delivering on agreements founded on an acceptable biosafety law.

\section{Early and continuous joint planning, sharing of information, and transparency encourages accountability and fosters trust building Joint and transparent planning sessions}

Despite the lack of formal documentation outlining the responsibilities of each partner institution at the inception of the project-as reported by the interviewees from the public institutions-their initial joint participation in developing the project proposal had established a strong foundation for ensuring accountability. Though the project was initially brought together by a need to unify the proposals of the three different countries for funding purposes, subsequent progress in the project reflected the value of transparent and joint planning sessions among the partners. During such meetings, financial matters were said to have been discussed openly among project partners in order to reinforce an environment of mutual accountability. The implementing partners also engaged in regular communication and information sharing, which enhanced trust. This pattern was seen through the project lifespan and was evidenced by commitment, mutual support and resource sharing - all of which contributed to building trust among the implementing partners. However, in retrospect, a TPRI partner interviewee felt that the planning could have been enhanced for better performance and trust among the partners in the project. Because of this apparent dissatisfaction with the planning, resources reserved for research were later used for non-core project activities such as holding meetings to make changes to project activities to accommodate unforeseen changes. As a result, interviewees acknowledged that there were delays in starting certain project activities, therefore necessitating a request to extend the project life.

\section{Sharing information and resources}

The sharing of resources and information is one outstanding feature of the Bt cotton project in East Africa that contributed to trust building. Information generated by any of the core partner institutions was shared among all the partners in the project through phone calls and exchange visits - all of which helped build trust. By relaying experiences including challenges and sharing data, interviewees described a mutual, collaborative relationship that enhanced trust and progress in the project. A free flow of information prevented overlaps in research and permitted scientists sufficient independence and a sense of confidence in each other.

On the topic of resource sharing, a scientist we interviewed from KARI alluded to the TPRI-KARI relationship, whereby KARI hosted Tanzania's trials in Kenya. Specifically, KARI provided land, transportation and other forms of facilitation at a subsidized rate, which helped cement trust between the two institutions. An academic from Makerere University described the practice of sharing information and resources as an accountable and collaborative approach which contributed to enhancing trust. Sharing of resources and information helped the parties synergize their strengths to improve project results. Spielman et al. [20] pointed out that synergies in agbiotech research may ideally lead to outcomes of greater quantity and with greater chances of success. We posit that the sharing of information and resources across the three countries served to build trust among the project partners and the data generated for regulatory approval may also contribute to a more unified regulatory regime in the region. 
3. Direct stakeholder engagement and awareness creation builds trust between project partners and the community Lack of public awareness and negative perception of GM crops

One factor that appeared to have contributed to slow regulatory approvals was limited awareness of GM technology among the public and specifically among government technical staff. Interviewees hypothesized that the suspicion surrounding the technology may stem from a lack of understanding of GM crops.

According to some interviewees, there is ignorance among frontline agricultural extension workers in East Africa, which is likely to influence the farmers' perceptions about, and trust in, GM crops. A recent study has shown that awareness of GM crops among members of the public and technical staff in Tanzania is poor [21]. An example of this stems from our interview with a biosafety regulator in Tanzania who stated that the public in Tanzania is not in favor of GM crops. Such skepticism, which leads to distrust in the technology, has been partly attributed to ideas propagated by misinformed media and anti-GM groups, which foster distrust between the project partners and the public. A stakeholder from KARI and another from AIRF identified the presence of anti-GM groups as contributing to the misrepresentation of GM crops. Negative and inaccurate perceptions fuelled by such groups were said to often reach farmers before they receive accurate information from the project partners, leading to misconceptions about GM crops.

We observed that lack of awareness about GM cropseven among public research institutions, regulatory institutions and ministries of agriculture-coupled with the delivery of inaccurate information to the public is likely to negatively influence public perception, and, in turn, impact regulatory decision-making processes.

\section{Negative views about private sector involvement}

The involvement of private multinational seed companies in the partnership also contributed to the community's distrust in the Bt cotton project. It has been reported that in sub-Saharan Africa the public holds unfavorable views about the involvement of the private sector in agbiotech projects [22]. Farmers, stakeholders from the seed sector, and non-governmental organizations (NGOs) focused on agriculture all view the involvement of private companies, particularly multinational ones, as being driven by a desire to monopolize the seed industry and therefore see the private sector as a potential threat to the food sovereignty of African countries [22]. The interviewees therefore perceived that public distrust about private sector involvement in the partnership stemmed from fear of corporate control of the seed technology and the view that the private sector seeks to make profits at the cost of the community. Part of this distrust was also said to be related to fear among members of the public that the Bt cotton would have the "terminator gene", which prevents the seed from germinating if re-planted (which is a common practice among farmers). A scientist from KARI emphasized the need to continuously assure the farmers that there is no terminator gene. Negative perceptions about the private sector (including Monsanto)-the source of the Bt cotton technology-only serves to strengthen skepticism about the technology, which may affect regulatory approval processes for the technology.

\section{Community engagement and awareness-building initiatives}

In view of the poor public awareness and negative perceptions about the private sector, there was an expressed urgency for enhanced public awareness of GM technology, as public perceptions can have negative repercussions not only on the regulatory process but also on the commercialization and adoption of the Bt cotton. Pre-conceived ideas about GM crops among members of the community, irrespective of their level of education, were said to likely render the process difficult. It has been reported that substantial public information about GM technology is useful both for regulatory processes and assuring the public of ownership of the project [23].

To gain the public's trust, the core partners engaged stakeholders at every level. KARI, for example, made use of their Bt cotton field trials to create awareness through a program called "Seeing-is-Believing," where journalists, politicians, farmers and government officials were taken for visits to the trial sites to allow them to make their own comparison of Bt cotton and conventional cotton. A scientist from KARI recognized the need for farmer engagement in GM technology development in order to boost adoption of this controversial technology. The visits help demystify the technology-and the processes of developing it-to members of the public.

An interviewee from AIRF in Tanzania noted that education and training of farmers were effective for enhancing public trust in Bt cotton, especially since seminars were held in local languages. At the same time, engaging the media was seen as a strategy to preventing alarmist reporting, and as such could facilitate trust building. These impacts were expected to translate, gradually, into the development of a regulatory framework that would enable broader exploitation of the GM crops in the region. In Uganda, a similar initiative was spearheaded by representatives from the Makerere University. An interviewee from the university reported the positive remarks made by farmers who had participated in the Seeing-isBelieving tours. An interviewee from the national regulatory authority in Uganda stated, "trust is known by what you do." These initiatives reflected well on the partners and helped build the public's trust in them.

Awareness creation through public education and the innovative "Seeing-is-Believing" tours provided an opportunity for multiple stakeholders to engage directly with 
researchers, compare the Bt cotton against the conventional varieties, and form their own opinions about the Bt cotton technology. Interviewees noted that the awareness creation measures led to a significant decline in negative perceptions of the Bt cotton technology and was helpful in building trust.

\section{Conclusion}

The international aspect of the Bt cotton project in East Africa presented distinct challenges to trust building. These challenges include: differences in the regulatory frameworks in the three countries; structural and management differences among the three partner institutions; and poor public awareness of GM crops and negative perceptions of the private sector - all of which contributed to delayed project implementation. The project partners tackled the structural and management differences among the three partner institutions through joint planning, harmonization of research protocols and management practices. Poor public awareness of GM crops and negative perceptions of the private sector were addressed through open communication and sharing of resources (as was the case between Kenya and Tanzania), and direct stakeholder engagement and awareness creation. These efforts contributed to enhancing trust among the public partners, leading to significant achievement of the project objectives.

Notwithstanding these positive outcomes, closer engagement of the private sector remained a challenge because of the differences in the regulatory frameworks in the three countries. Whereas the regulatory frameworks in Kenya and Uganda were favorable to private sector involvement, the regulatory framework in Tanzania was not. The failure to conduct field trials of Bt cotton in Tanzania emphasizes the need for regulatory regimes that can serve as a foundation for trust building between the public and private sector. The Bt cotton project in East Africa failed to attract a private sector player into its partnership due to the regulatory differences. Effective private sector involvement relies on acceptable biosafety regulations that will boost the private sector's confidence in sharing their proprietary technologies.

\section{Additional material}

Additional file 1: Core partners in the Bt cotton East Africa project. Additional file 2: Sample questions from the open-ended interview guide.

\section{Acknowledgements}

The authors are grateful to each of the participants who contributed substantial time and effort to this study. Special thanks to Jessica Oh, Nadira Saleh and Jocalyn Clark for comments on earlier drafts of the manuscript. This project was funded by the Bill \& Melinda Gates Foundation and supported by the Sandra Rotman Centre, an academic centre at the
University Health Network and University of Toronto. The findings and conclusions contained within are those of the authors and do not necessarily reflect official positions or policies of the foundation. This article has been published as part of Agriculture \& Food Security Volume 1 Supplement 1, 2012: Fostering innovation through building trust: lessons from agricultural biotechnology partnerships in Africa. The full contents of the supplement are available online at http://www.agricultureandfoodsecurity. com/supplements/1/S1. Publication of this supplement was funded by the Sandra Rotman Centre at the University Health Network and the University of Toronto. The supplement was devised by the Sandra Rotman Centre.

\section{Author details}

'Sandra Rotman Centre, University Health Network and University of Toronto, Toronto, Ontario, Canada. ${ }^{2}$ African Centre for Innovation and Leadership Development, Federal Capital Territory, Abuja, Nigeria. ${ }^{3}$ Dalla Lana School of Public Health, University of Toronto, Toronto, Canada. ${ }^{4}$ Grand Challenges Canada. ${ }^{5}$ Dalla Lana School of Public Health and Department of Surgery, University of Toronto, Toronto, Canada.

\section{Authors' contributions}

Study conception and design: OCE, JM, ASD. Data collection: JM and OCE. Analysis and interpretation of data: JM and OCE. Draft of the manuscript: JM and OCE. Critical revision of the manuscript for important intellectual content: OCE, JM and ASD. All authors read and approved the final manuscript.

\section{Competing interests}

The authors declare that they have no competing interests.

Published: 1 November 2012

\section{References}

1. FAOSTAT. [http://faostat.fao.org/site/342/default.aspx;].

2. Tanzania Cotton Board: Annual report and accounts for the year ending on 30th June 2010, Pamba House, Garden Avenue P.O. Box 9161, Dar es Salaam. 2010.

3. Cotton Development Authority (CODA). [http://www.cottondevelopment. co.ke/pages/The_Cotton_Industry.vrt].

4. FAOSTAT. [http://faostat.fao.org/site/567/DesktopDefault.aspx? PagelD=567\#ancor].

5. Wakhungu WJ, Wafula DK: Introducing Bt Cotton Policy Lessons for Smallholder Farmers in Kenya. 2004, 84

6. The Republic of Uganda, Ministry Of Agriculture, Animal Industry and Fisheries: Cotton value chain study in Lango and Acholi sub-regions. Plan for modernisation of Agriculture (PMA). 2009.

7. Clive J: Biotech and organic agriculture proponents have to work together to boost Africa's food security. Crop Biotech Update 2012.

8. Republic of Kenya: The Biosafety Act, 2009. In Kenya Gazette Supplement. Volume 10. Nairobi, Kenya: Government Printer; 2009(Act No. 2).

9. African Agricultural Technology Foundation: Biotech cotton in Uganda: Potential benefits, challenges \& way forward. 2010, 1-17.

10. Space Daily. [http://www.spacedaily.com/news/food-05c.html].

11. Daily News Online Edition. [http://dailynews.co.tz/index.php/parliamentnews/1682-from-the-parliament21].

12. Republic of Tanzania: The National Biosafety Framework for Tanzania. 2004.

13. Biovision East Africa. [http://www.biovisioneastafrica.com/publications/BBl\% 20Article.pdf].

14. Friedberg SE, Horowitz L: Converging networks and clashing stories: South Africa's agricultural biotechnology debate. Africa Today 2004, 51(1):3-25.

15. Stone GD: Both Sides Now. Fallacies in the genetic-modification wars, implications for developing countries and anthropological perspectives. Current Anthropology 2002, 43(4):611-630.

16. Ezezika OC, Thomas F, Lavery JV, Daar AS, Singer PA: A social audit model for agro-biotechnology initiatives in developing countries: accounting for ethical, social, cultural and commercialization issues. Journal of Technology Management and Innovation 2009, 4(3):24-33.

17. Yin RK: Case study Research: Design and Methods. California: Sage Publications; 42003 
18. Mabeya J, Singer PA, Ezezika OC: The role of trust building in the development of biosafety regulations in Kenya. Law, Environment and Development Journal 2010, 6/2:218-227.

19. Republic of Uganda: National Biotechnology and Biosafety Policy. 2008.

20. Spielman DJ, Cohen Jl, Zambrano P: Policy, investment, and partnerships for agricultural biotechnology research in Africa: Emerging evidence. ATDF Journal 2006, 3(4):3-9.

21. Lewis CP, Newell JN, Herron CM, Nawabu H: Tanzanian farmers' knowledge and attitudes to GM biotechnology and the potential use of GM crops to provide improved levels of food security. A Qualitative Study. BMC Public Health 2010, 10:407.

22. Ezezika OC, Daar AS, Barber K, Mabeya J, Thomas F, Deadman J, Wang D, Singer PA: Factors influencing agbiotech adoption and development in sub-Saharan Africa. Nature Biotechnology 2012, 30:38-40.

23. Proceedings of the Harnessing the Potential of Biotechnology for Food Security and Socioeconomic Development in Africa: 22-26 September 2008; Nairobi, Kenya. African Biotechnology Stakeholders Forum; Nzuma JM 2008.

doi:10.1186/2048-7010-1-S1-S8

Cite this article as: Ezezika et al.: Harmonized biosafety regulations are key to trust building in regional agbiotech partnerships: the case of the Bt cotton project in East Africa. Agriculture \& Food Security 2012

1(Suppl 1):S8.

\section{Submit your next manuscript to BioMed Central} and take full advantage of:

- Convenient online submission

- Thorough peer review

- No space constraints or color figure charges

- Immediate publication on acceptance

- Inclusion in PubMed, CAS, Scopus and Google Scholar

- Research which is freely available for redistribution

Submit your manuscript at www.biomedcentral.com/submit 